\title{
INTRODUCTION
}

\section{Epidemiological Studies in Japan}

\author{
Tomio Hirohata
}

The present article provides an overview of epidemiological studies in Japan. The origin of modern epidemiology of Japan can be traced back into the late 19th century. Baron K. Takaki at that time made brilliant epidemiological studies on beriberi and was thus able to eradicate the disease long before vitamin $B_{1}$ deficiency was identified as the cause of the disease.

Epidemiological studies really began to flourish in Japan after the end of World War II. Since the most of infectious diseases have been controlled, epidemiological studies on cancer, heart disease, stroke, and other chronic diseases have become the main target of investigations. It may be cautioned that, among infectious diseases, tuberculosis is still a serious health problem today and HIV infection has become a threatening health issue although the number of AIDS patients reported was still about 1,000 for the whole country in 1995. In contrast to other industrialized countries, heart disease is far less common in Japan, probably reflecting still nottoo-rich diet among Japanese. There are a number of unique or unusual epidemiological studies in Japan, including a long-term surveillance of those who were exposed to A-bomb irradiation in 1945. Readers are encouraged to refer to detailed description of each, specific topic presented in this volume.

Essential vital statistics are also presented as background information of epidemiological studies in Japan. J Epidemiol, $1996 ; 6:$ S13-S17.

epidemiological study, chronic disease, vital statistics, Japan

The present article provides an overview of epidemiological studies of Japan. This seems timely because the 14 th International Epidemiological Association meeting will be held in Nagoya in August. 1996. Regarding health, the Japanese presently enjoy good health conditions. As of 1994, life expectancy at birth is 76.6 years for males and 83.0 years for females, while as of 1993, the infant mortality rate is 4.35 per 1,000 live births. Those figures are among the best statistics world-wide and reflect the excellent health conditions of the country. Despite numerous health problems today, as far as the above statistics are concerned, Japanese indeed seem to enjoy high standard of health. A few theories may be considered to explain the above phenomena.

In the first place, the national compulsory insurance system provides every individual with easy access to medical resources. Secondly, the diet of Japanese is still not too rich despite economical development, and the energy intake from fat remains about $25 \%$ of the total energy intake. Mortality from coronary heart disease is, therefore, far less common in Japan as compared with other industrialized countries. Lastly, Japan is an island nation with an ethnically homogeneous population. As a result, there are no particular health issues related to minority groups.

Regarding the future outlook of the nations health, however, the fact that the proportion of elderly population (age 65 and over) is rapidly increasing and is expected to reach about $25 \%$ of the population in 2020 , which is an unprecedented figure in the world, surely impose a serious threat to the nation's future health. The birth rates have shown a continuous decline over the last few decades and the net reproduction rate reached an all- time low of 0.70 in 1993 , which is one of the major causes of the rapid aging of the Japanese society. Those comments offer amall glimpses of the nation's health and readers are suggested to refer to each topic of this volume for a more detailed presentation and discussion.

Received and accepted April 3, 1996.

Department of Food and Nutrition Sciences, Nakamura Gakuen University, Fukuoka, Japan.

Address for correspondence : Tomio Hirohata, Department of Food and Nutrition Sciences, Nakamura Gakuen University, 5-7-1 Befu Jonan-ku Fukuoka, 814-01 Japan. 


\section{THE DAWN OF EPIDEMIOLOGY IN JAPAN}

Although epidemiological studies began to flourish only after the end of World War II, the origin of epidemiologic studies in Japan can be traced back to as early as in the 1880's. Baron Kanehiro Takaki (1849-1920) made brilliant epidemiologic studies on beriberi and was thus able to eradicate the disease long before vitamin $B_{1}$ deficiency was identified as the cause of the disease $(1,2)$. As a naval officer, he encountered many beriberi patients who occupied as many as three quarters of the beds of the naval hospital in Tokyo in the late 1870's.

After having been trained at the St. Thomas Hospital Medical School in London, he began to search for a way to prevent this devastating disease by means of an epidemiologic approach. He found no association of the disease with clothing, drinking water, living quarter, sleeping hours, climate, etc. However, longer voyages tended to increase the occurrence of this disease and officers were less likely to develop it than sailors. At that time, outside Japan, beriberi was practically unknown among the Western European countries.

Based on epidemiological investigation, he deduced that very heavy dependence on polished rice in the diet among the Japanese was the likely cause of the disease and thus advocated to modify the navy diet by increasing the consumption of meat, milk, vegetable and bread product. In 1882, a training ship, Ryujyo, sailed the Pacific Ocean for 272 days with a tragic epidemic of beriberi. Nearly half of the 370 men on board developed the disease resulting in 25 deaths. Takaki was then able to persuade the navy to let another training ship, Tsukuba, sail while the sailors all consumed Takaki's modifid diet and following the same route and during the same season as that of ill-fated Ryujyo. After this long voyage, only a few out of the 333 men on board developed the disease with no fatal cases.

As Table 1 shows, the incidence of beriberi ranged from 250 to 400 per 1,000 of naval personnel from 1878 to 1883 . After the introduction of Takaki's improved diet in 1884, the inci- dence rate dropped to only 5.93 in 1885 , then further fell to 0.35 in 1886, and null thereafter. Takaki's brilliant success in controlling beriberi by epidemiologic investigations took place a quarter century before vitamin $B_{1}$ deficiency was identified as the cause of the disease. Indeed, as noted by Dr. Itokawa in the Journal of Nutrition (3), Takaki was the first person to produce actual evidence suggesting the existence of vitamins. His pioneer work in nutritional epidemiology should therefore be long remembered in Japanese epidemiological studies.

\section{ESSENTIAL VITAL EVENTS RELATING TO EPIDEMIOLOGICAL INVESTIGATIONS}

Table 2 shows the 10 leading causes of death in Japan for both sexes in 1994. The top three, malignant neoplasms, heart diseases, and cerebrovascular diseases accounted for $59.7 \%$ of the total deaths. Although malignant neoplasms ranked at the top of the list, the disease is less common than the rates seen in other industrialized countries. For example, the age-adjusted mortality rate from malignant neoplasms in Japan is only $81 \%$ and $83 \%$ that observed in England and Wales and Germany, respectively, for males from 1983-87.

As is well known, heart disease is the top killer in the most industrialized countries. Japan shows a far lower mortality for this disease, which contributs greatly to the lower death rate from all causes of deaths. In contrast, cerebrovascular accident (stroke) has been more prevalent than in other countries.

Table 3 shows the time trend of five leading causes of death from 1950 to 1990. In 1950, tuberculosis was at the top of the list followed by cerebrovascular diseases. Cerebrovascular diseases remained at the top of the list for approximately 30 years from 1951-1980. Since 1981, however, malignant neoplasms have become the leading cause of deaths.

Table 4 shows time trend of the crude- and age-adjusted death rates and infant death rates. It is clear to see that Japanese experienced a great reduction in the risk for death

Table 1. Time trend of incidence of and mortality from beriberi

\begin{tabular}{lccccr}
\hline & Strength & $\begin{array}{c}\text { No. of } \\
\text { Patients }\end{array}$ & $\begin{array}{c}\text { Incidence } \\
\text { per 1,000 }\end{array}$ & $\begin{array}{c}\text { No. of } \\
\text { Deaths }\end{array}$ & $\begin{array}{r}\text { Mortality } \\
\text { per } 1,000\end{array}$ \\
\hline 1878 & 4528 & 1485 & 327.96 & 32 & 7.07 \\
1879 & 5031 & 1978 & 389.29 & 57 & 11.20 \\
1880 & 4956 & 1725 & 348.06 & 27 & 5.45 \\
1881 & 4641 & 1163 & 250.59 & 30 & 6.46 \\
1882 & 4769 & 1929 & 404.49 & 51 & 10.69 \\
1883 & 5346 & 1236 & 251.20 & 49 & 9.17 \\
1884 & 5638 & 718 & 127.35 & 0 & 1.42 \\
1885 & 6918 & 41 & 5.93 & 0 & 0 \\
1886 & 8475 & 3 & 0.35 & 0 & 0 \\
1887 & 9016 & 0 & 0 & 0 & 0 \\
1888 & 9184 & 0 & 0 & & 0 \\
\hline
\end{tabular}


during the approximately 40 year period between 1950 and 1993. The age-adjusted death rates decreased from 18.6 to 7.3 per 1,000 which means $60 \%$ reduction for males and from 14.6 to 4.0 or a $73 \%$ reduction for females. The decline in infant death rate was even more phenomenal with a rate of 4.3 per 1,000 live births in 1993 which was only $7.2 \%$ of the 60.1 rate observed in 1950.

In contrast to the very favorable statistics cited above, the birth rates in Japan have shown a remarkable continuous decline for the last 40 years and net reproduction rate reached all-time low of 0.70 in 1993 . Thus, Japanese population is predicted to decline in the future. Due to the shrinking population of the younger age group, proportion of the elderly population aged 65 and over in the total population is therefore predicted to show a drastic increase and is expected to reach about $25 \%$ in 2020, which would be an unprecedented high rate worldwide. This development, of course, casts a great shadow on the future health conditions in Japan.

Table 2. The ten leading causes of death in Japan for both sexes, 1994

\begin{tabular}{|c|c|c|c|c|}
\hline & & & Death & \\
\hline & Cause of Death & $\begin{array}{c}\text { No. of } \\
\text { Death }\end{array}$ & $\begin{array}{c}\text { Rate per } \\
100,000\end{array}$ & $\begin{array}{l}\text { Propor- } \\
\text { tion }(\%)\end{array}$ \\
\hline 1 & Malignant Neoplasms & 243,585 & 196.3 & 27.8 \\
\hline 2 & Heart Diseases & 159,485 & 128.5 & 18.2 \\
\hline 3 & Cerebrovascular Diseases & 120,225 & 96.9 & 13.7 \\
\hline 4 & Pneumonia and Bronchitis & 89,789 & 72.4 & 10.3 \\
\hline 5 & Accidents & 35,934 & 29.0 & 4.1 \\
\hline 6 & Senility & 23,452 & 18.9 & 2.7 \\
\hline 7 & Suicide & 20,889 & 16.8 & 2.4 \\
\hline 8 & Nephritis, Nephrosis & 18,768 & 15.1 & 2.1 \\
\hline 9 & Chronic Liver Disease and Cirrhosis & 16,432 & 13.2 & 1.9 \\
\hline 10 & Diabetes Mellitus & 10,868 & 8.8 & 1.2 \\
\hline
\end{tabular}

Source : Vital statistics report, Ministry of Health and Welfare, Japan

Table 3. Time trend of the five leading causes of death in Japan for both Sexes

\begin{tabular}{|c|c|c|c|c|c|c|c|c|c|c|}
\hline & \multicolumn{2}{|l|}{1} & \multicolumn{2}{|l|}{2} & \multicolumn{2}{|l|}{3} & \multicolumn{2}{|c|}{4} & \multicolumn{2}{|c|}{5} \\
\hline & Cause & Rate $^{l)}$ & Cause & Rate") & Cause & Rate' & Cause & Rate') & Cause & Rate $^{1)}$ \\
\hline 1950 & Tuberculosis & 146.4 & $\begin{array}{l}\text { Cerebrovascular } \\
\text { Diseases }\end{array}$ & 127.1 & $\begin{array}{l}\text { Pneumonia and } \\
\text { Bronchitis }\end{array}$ & 93.2 & $\begin{array}{l}\text { Gastro- } \\
\text { intestinal } \\
\text { Diseases }\end{array}$ & 82.4 & $\begin{array}{l}\text { Malignant } \\
\text { Neoplasms }\end{array}$ & 77.4 \\
\hline 1960 & $\begin{array}{l}\text { Cerebrovascular } \\
\text { Diseases }\end{array}$ & 160.7 & $\begin{array}{l}\text { Malignant } \\
\text { Neoplasms }\end{array}$ & 100.4 & Heart Diseases & 73.2 & Senility & 58.0 & $\begin{array}{l}\text { Pneumonia } \\
\text { and } \\
\text { Bronchitis }\end{array}$ & 49.3 \\
\hline 1970 & $\begin{array}{l}\text { Cerebrovascular } \\
\text { Diseases }\end{array}$ & 175.8 & $\begin{array}{l}\text { Malignant } \\
\text { Neoplasms }\end{array}$ & 116.3 & Heart Diseases & 86.7 & Accidents & 42.5 & Senility & 38.1 \\
\hline 1980 & $\begin{array}{l}\text { Cerebrovascular } \\
\text { Diseases }\end{array}$ & 139.5 & $\begin{array}{l}\text { Malignant } \\
\text { Neoplasms }\end{array}$ & 139.1 & Heart Diseases & 106.2 & $\begin{array}{l}\text { Pneumonia } \\
\text { and } \\
\text { Bronchitis }\end{array}$ & 33.7 & Senility & 27.6 \\
\hline 1990 & $\begin{array}{l}\text { Malignant } \\
\text { Neoplasms }\end{array}$ & 177.2 & Heart Diseases & 134.8 & $\begin{array}{l}\text { Cerebrovascular } \\
\text { Diseases }\end{array}$ & 99.4 & $\begin{array}{l}\text { Pneumonia } \\
\text { and } \\
\text { Bronchitis }\end{array}$ & 60.7 & Accidents & 26.2 \\
\hline
\end{tabular}

Source : Vital statistics report, Ministry of Health and Welfare, Japan

1) Crude rate per 100,000 population 
Table 4. Time trend of the crude and age-adjusted death rates and the infant death rates

\begin{tabular}{|c|c|c|c|c|c|}
\hline & \multicolumn{2}{|c|}{ Crude Death Rates" } & \multicolumn{2}{|c|}{$\begin{array}{l}\text { Age-adjusted Death } \\
\text { Rates }\end{array}$} & \multirow[t]{2}{*}{$\begin{array}{c}\text { I nfant Death } \\
\text { Rates }^{3)}\end{array}$} \\
\hline & Male & Female & Male & Female & \\
\hline 1950 & 11.4 & 10.3 & 18.6 & 14.6 & 60.1 \\
\hline 1960 & 8.2 & 6.9 & 14.8 & 10.4 & 30.7 \\
\hline 1970 & 7.7 & 6.2 & 12.3 & 8.2 & 13.1 \\
\hline 1980 & 6.8 & 5.6 & 9.2 & 5.8 & 7.5 \\
\hline 1990 & 7.4 & 6.0 & 7.5 & 4.2 & 4.6 \\
\hline 1993 & 7.8 & 6.4 & 7.3 & 4.0 & 4.3 \\
\hline
\end{tabular}

Source: Vital statistics report, Ministry of Health and Welfare, Japan

$\begin{array}{llll}\text { 1) Rates per 1,000 } & \text { 2) Age-adjusted using } 1985 \text { modified Japanese population as standard } & \text { 3) Rates per 1,000 live births }\end{array}$

\section{A BRIEF OVERVIEW OF EPIDEMIOLOIGICAL STUDIES IN JAPAN}

As stated earlier, malignant neoplasms have been the leading cause of deaths in Japan since 1981. Three articles on cancer studies are presented in this volume, i. e., research activities (Watanabe, S.), international cooperative research (Tominaga, S.), and cancer registry (Fujimoto, I.). Besides, ongoing largescaled cohort studies (Aoki, K.) has also much relevance to cancer research. Metabolic epidemiology (Kamiyama, S.), molecular epidemiology (Nakachi, K.) and sero-epidemiology (Sasaki, R.) are also much related to cancer research. National community screening programs of cancer and cardiovascular diseases (Hisamichi, S.) have neen initiated.

Two prominent researchers have contributed greatly to the development of cancer epidemiology in Japan. The late professor M. Segi published a series of monographs on cancer mortality statistics in the world (4). He published the ageadjusted death rates of various cancer sites in 24 countries in the world, which was indeed a pioneer work of comparative cancer epidemiology. The late Dr. T. Hirayama also gained prominence for his cohort study on a population of nearly a quarter million people for 17 years (5). Recent epidemiological study on cancer have become more multi-disciplinary and included the recent advances in molecular biology. The readers are advised to read the relevant articles for a more detailed presentation.

Heart diseases are the second leading cause of death. As stated earlier, the proportion of energy intake from fat in total energy intake remains at approximately $25 \%$. Ischemic heart disease, a major component of heart disease, is thus far less common in Japan than other industrialized countries, reflecting the generally healthy dietary habits of the Japanese. Although the readers should refer to the article on ischemic heart disease (Tanaka, H.), it may be pointed out that significant international comparison studies have been conducted since the 1960's, taking advantage of huge difference in risks for the disease between Japan and abroad $(6,7)$.

In contrast to heart disease, cerebrovascular disease tends to be more prevalent in Japan, particularly in the Tohoku region, northern part of the country. However, the age-adjusted death rate from cerebrovascular disease declined $72 \%$ during the period from 1960 to 1990 . Readers are encouraged to refer to the article on the epidemiology of cerebrovascular disease, stroke epidemic in Japan (Shimamoto, T.).

With regard to infections diseases, tuberculosis used to be very prevalent, and was the leading cause of death from around 1930 to 1950 . The disease is still prevalent and about 50,000 new cases were reported to tuberculosis registry in 1993 (tuberculosis, Aoki, M.). Recently, AIDS has become a new major health threat, however, the number of AIDS patients reported is still less than 1,000 in 1995. Even though the number of AIDS patients is predicted to reach nearly 3,000 in 1997 , the number of such patients is still dramatically less than that observed in the most other countries (HIV infection, Tajima, K.).

The Radiation Effects Research Foundation (formerly the Atomic Bomb Casualty Commission) has been following Abomb survivors and the controls consisting of about 100,000 subjects since 1950 to detect possible late health effects due to irradiation (Kodama, K.). It is noteworthy that national community screening programs on cancer and cardiovascular diseases are currently underway. After the tragic SMON episode in the late 1960's in Japan, a large amount of public funds has been spent for the treatment and research of diseases of unknown etiology specified as intractable diseases (Ohno, Y.).

Space limitations do not allow for a complete description of all aspects of epidemiological studies in Japan and a few important fields were thus not included in this brief article. However, it is hoped that the readers were thus able to obtain a general idea about epidemiology in Japan. For more detailed descriptions and discussions, the readers are suggested to refer to each article on the specific topics covered in this volume.

\section{REFERENCES}

1. Takaki K. The preservation of health amongst the personnel of the Japanese navy and army, lecture I. Lancet, 
$1906 ; 1: 1369-1374$.

2. Takaki K. ibid. , lecture II. Lancet, $1906 ; 1$ : 1451-1455.

3. Itokawa Y. Kanehiro Takaki (1849-1920), a biographical sketch. J Nutrition, 1976 ; 106 : 583-588.

4. Segi $\mathbf{M}$, et al. Cancer mortality in 24 countries, No. 1No. 6. Dept. of Public Health, School of Medicine, Tohoku Univ., Sendai, Japan, 1960-1972.

5. Hirayama $T$. Life-style and mortality ; a large-scale census-based cohort study in Japan. Karger, Basel,
Munchen, Paris, London, New York, and Tokyo, 1990.

6. Toshima $\mathrm{H}$, Koga $\mathrm{Y}$, Blackburn $\mathrm{H}$ and Keys $\mathrm{A}$ eds. Lessons for science from the seven countries study ; a 35-year collaborative experience in cardiovascular disease epidemiology. Springer-Verlag, Tokyo, 1994.

7. Yano K, MacLean CJ, Reed DM, et al. A comparison of the 12-year mortality and predictive factors of coronary heart disease among Japanese men in Japan and Hawaii. Am J Epid, 1988 ; 127 : 476-487. 